ISSN-0275-4207

\section{THE BIOTECHNOLOGY NEWS SOURCE ${ }^{\mathrm{TM}}$}

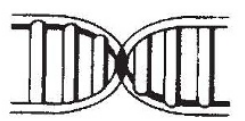

BioEngineering News -

the only biweekly

newsletter covering the

genetic-engineering

recombinant-DNA,

monoclonal-antibody,

and cell-culture

industries.

24 issues $-\$ 236.00$ (U.S.) ( $\$ 195.00$ in U.S. \& Canada)

Subscriptions sent airmail.

Write: BioEngineering News, Suite 304, 109 Minna St., San Francisco, CA 94105. Tel: (415) 332-0508.

Telex: 171463-HQLARK.

Special Reports Available: (1) Genetic Engineering Industry, (2) Hybridoma \& Cell Fusion, (3) Automated DNA Synthesizers. Price: $\$ 29.95$ (U.S. Funds).

NOTE - For prepaid subscriptions select any two (2) reports as a bonus.

Circle No.04 on Reader Enquiry Card.

\section{MICROCOMPUTERS} and PHYSIOLOGICAL SIMULATION

\section{Lames R. Kandall.}

\section{! $\quad$ Mrlim}

"Here is where Dr. Randall's book is invaluable: the background information on microprocessors combined with specific examples of biological data simulated with various hardware and software configurations, should allow any lifesoftware configurations, should allow any lifescience experimenter to progress rapidly from BYTE
BYitial idea to a working simulation model." Contents:

Introduction. Microcomputer Components. Operating Systems and Programming Languages. Hardware Enhancements for Simulation. Representative Microcomputers. Compartmental Kinetics: A First Example. The Glucose Tolerance Test. Cardiovascular System Mechanics. Arterial Pulse Pressure. Vectorcardiography and the Limb Leads. Distortion of Waveforms. Axon Action Potentials. Cardiac Action Potentials. Formatting Student Exercises. Index.

1980. 250 pp., illus. Paper $06128 \$ 14.50$

Brochure Available from Publisher. Price is subject to change without notice. Price higher outside UIS.A

\section{Addison-Wesley}

Advanced Book Program,

World Science Division

Reading. Mass. 01867, U.S.A

London, Amsterdam, Jon Mills, Ontario, Sydney, Tokyo Circle No.11 on Reader Enquiry Card.

\title{
Some worthy publicity for elastin
}

\section{A. Serafini-Fracassini}

Biology and Pathology of Elastic Tissues. Frontiers of Matrix Biology, Vol.8. Edited by A.M. Robert and L. Robert. Pp.230. (S. Karger: 1980.) \$74.25, SwFr.124.

THIS book attempts to expound, for the benefit of graduate students and professional investigators, various areas of scientific research which are contained within the subject of molecular biology and pathology of elastin. This is undoubtedly a topic of considerable importance to biochemical and medical workers, and one which has attracted a large amount of research over the past two decades. As unambiguous interpretations of functional properties of the protein still prove elusive, it is of some value to have, brought together in one volume, a collection of critical evaluations of some recent findings. The earlier contributions in the book deal with structural and conformational aspects of the protein, while the others discuss its implication in the inflammatory response and in some tissue disorders. The role of elastases in these pathological conditions is adequately outlined. However, in this context, one would like to have seen included an up-todate account of the biosynthesis of elastin, with particular reference to the nature of the soluble biosynthetic intermediate and

\section{Compleat diquat and paraquat}

\section{R.J. Hance}

The Bipyridinium Herbicides. By L.A. Summers. Pp.449. (Academic: 1980.) £33, $\$ 79.50$.

ONLY two bipyridinium herbicides, diquat and paraquat, are in widespread use, so it is interesting to speculate why they have stimulated a book of this size when larger groups of herbicides have not. Perhaps there are two reasons. The first is the enthusiasm of Dr Summers for his subject. The second is that, in comparison with other herbicides, the peripheral synthetic chemistry of these compounds is challenging and their toxicology unusual. Indeed, these topics occupy almost half the book. The remainder covers the chemistry of the respective diquaternary salts, structure-activity relationships, environmental fate, occurrence and analysis of residues, herbicidal use and modes of action.

With 2,500 references cited in little over 400 pages the text is hard going in places but, by intelligent use of tables, the author has done his best to avoid producing a catalogue. The only reasonable criticism that might be made is that not all readers will follow the logic underlying the sequence in which subjects are presented. to the biogenesis of the cross-links. Such a chapter would have been of great value to an outsider to the subject in appreciating the significance of some structural features of the protein and in understanding the pathogenesis of specific disorders. Other aspects which with advantage could have been covered more fully are the physicochemical properties of elastin, and the thermodynamics of its deformation to balance Dr Urry's excellent contribution on synthetic repeat polypeptides.

It is difficult to make a unified judgement on this collection of papers because the style of the contributions is so varied. Some offer an accurate review of the relevant scientific research, while others mainly outline the results obtained in the authors' laboratories, occasionally with the exclusion of some lines of research that might have merited discussion. This is also reflected by the variable number of references cited at the end of each chapter.

The book is well produced, adequately illustrated and as a whole very readable. Elastin has not yet enjoyed its share of the general escalation in scientific publications, and I consider this a worthy collection, one which could be read with profit in its entirety by non-specialists.

A. Serafini-Fracassini is Professor of Biochemistry at the University of St Andrews.
For instance, the chapters dealing with fate in biological systems and with residues are separated from that on toxicology and environmental effects which in many respects is closely related. The layout within chapters also occasionally seems strange. There is a good example on p.394, where a paragraph describing the most effective ways of treating paraquat poisoning is placed in the middle of a section rather than at the end where it would have more impact. However, the book is sensibly indexed so the reader should have little difficulty in finding specific information.

Nowadays, books including a range of specialist subjects tend to be multiauthored. For one man to tackle such a task successfully is an impressive feat of scholarship and Dr Summers deserves warm congratulation. His book undoubtedly will become a standard reference. It shows, incidentally, that there remains a place for books of this type alongside the computer-based information retrieval systems that seem to threaten their viability.

$R$. J. Hance is leader of the Herbicide Group at the Agricultural Research Council Weed Research Organization, Yarnton, near Oxford. 